\title{
A IMAGEM CRONICAMENTE IMPERFEITA: O CORPO E A CÂMERA ENTRE OS MEBÊNGÔKRE-KAYAPÓ
}

DIEGO MADI DIAS

UFRJ

ANDRÉ DEMARCHI ${ }^{1}$

UFRJ

\begin{abstract}
RESUMO: A produção audiovisual indígena atinge, nesse início de século, um momento de consolidação que está relacionado a um crescente interesse (geral e indígena) acerca das ideias de cultura e imagem. O caso tratado aqui guarda uma peculiaridade histórica na medida em que o uso do vídeo pelos Kayapó data do final da década de 1980. O artigo discute a relação entre a prática de vídeo e o regime sócio-cosmológico desse grupo, no âmbito do contato interétnico, destacando a importância da relação entre o corpo e a câmera. Recorremos ao juízo estético mebêngôkre sobre a imagem filmada para demonstrar a impossibilidade de produção de uma imagem "bela" (mejx).
\end{abstract}

PALAVRAS-CHAVE: Imagem; Corpo; Beleza; Contato; "Cultura".

ABSTRACT: The indigenous audiovisual production reaches, at the beginning of this century, a period of consolidation that seems related to a growing interest (both general and indigenous) in the notions of culture and image. In the Kayapo case, a historical quirk remains as the use of video goes back to the late 1980's. This paper discusses the relationship between the practice of videomaking and the socio-cosmological system of this group, in the context of inter-ethnic contacts, highlighting the importance of the relationship between the body and the camera. We used the Mebengokre aesthetic judgment on the filmed images in order to demonstrate the impossibility of producing a beautiful image.

KEYWORDS: Image; Body; Beauty; Contact; "Culture".

\footnotetext{
${ }^{1}$ Diego Madi Dias e André Demarchi são alunos de doutorado pelo Programa de Pós-Graduação em Sociologia e Antropologia, PPGSA, IFCS, UFRJ. Os autores realizaram pesquisa de campo, em conjunto, nos períodos de abril a maio de 2009 e de dezembro de 2009 a janeiro de 2010, nas aldeias Moxkarakô e Kokraimoro, próximas à cidade de São Félix do Xingu, Pará. A pesquisa foi financiada pelo programa de Documentação de Línguas e Culturas Indígenas, da UNESCO, realizado no Museu do Índio - FUNAI. No caso kayapó, a execução se deu através de convênio entre o Museu do Índio, o NAIPE (Núcleo de Arte, Imagem e Pesquisa Etnológica) e o NEXTIMAGEM (Núcleo de Experimentações em Etnografia e Imagem), ambos pertencentes ao Programa de Pós-Graduação em Sociologia e Antropologia, do Instituto de Filosofia e Ciências Sociais, da Universidade Federal do Rio de Janeiro. Como contrapartida ao financiamento concedido pela UNESCO, via Museu do Índio, os autores realizaram, em campo, oficinas de audiovisual com indígenas das duas aldeias kayapó já citadas. Basicamente, os dados analisados aqui provêm dessa experiência, que teve também como resultado o filme Memudjê (2010), dentre outros produtos. Os autores agradecem ao CNPq, à CAPES e à FAPERJ pelas bolsas concedidas durante a

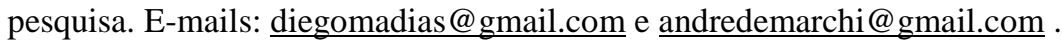

Espaço Ameríndio, Porto Alegre, v. 7, n. 2, p. 147-171, jul./dez. 2013. 


\section{Preâmbulo}

O discurso não é simplesmente aquilo que manifesta (ou oculta) o desejo; é, também, aquilo que é objeto do desejo (...) não é simplesmente aquilo que traduz as lutas ou os sistemas de dominação, mas aquilo por que, pelo que se luta, o poder do qual queremos nos apoderar.

Foucault (1996, p. 10)

A maneira como os Kayapó ${ }^{2}$ utilizam o vídeo foi objeto de reflexão de Terence Turner em Defiant Images - The Kayapo appropriation of video, artigo publicado na Anthropology Today em dezembro de 1992 e resultado da palestra de Turner na ocasião da visita de Mokuká Kayapó e Tamok Kayapó ao RAl's Third International Festival of Ethnographic Film (Granada Television).

Neste artigo, Turner, ao refletir sobre o uso do vídeo pelos Kayapó, confere ênfase especial ao momento da filmagem como um modo de exercício do poder, ato capaz de mediar uma variedade de relações sociais e políticas de maneira ainda mais decisiva que o próprio documento fílmico. Conforme notado pelo autor, a prática de filmagem constitui, em si mesma, uma maneira privilegiada de tecer relações com a cultura ocidental dominante. Em suas palavras, "Kayapo, in short, quickly made the transition from seeing video as a means of recording events to seeing it as an event to be recorded" (TURNER, 1992, p. 7).

A partir de uma concepção do discurso conforme expressa pela epígrafe, parece ser possível tratar de uma dimensão central das discussões sobre empoderamento étnico através das mídias audiovisuais: a passagem de objeto a sujeito em um contexto de relação assimétrica. Essa passagem, articulada com os dados da etnologia mebêngôkre, evoca questões essenciais acerca de corporalidade,

\footnotetext{
${ }^{2}$ A terra indígena Kayapó (TI Kayapó) está localizada ao sul do Estado do Pará e ao norte do Estado do Mato Grosso. Os Kayapó (Mebêngôkre) são falantes da língua kayapó, da família linguística Jê. Sua população atual é de 6.000 pessoas (2006) espalhadas por diversas aldeias ao longo dos afluentes do rio Xingu.
} 
identidade, alteridade e relacionalidade.

\title{
The Kayapo Video Project
}

O The Kayapo Video Project foi um projeto de capacitação indígena para o uso de ferramentas e recursos audiovisuais. Sua criação seguiu motivações políticas, mas logo Terence Turner percebeu o rendimento teórico oferecido pela mídia indígena para pensar o contato interétnico. Retomando a distinção proposta por Faye Ginsburg, Turner procura estabelecer diferença entre a mídia indígena e a produção de filmes etnográficos (realizados por antropólogos ou outros não índios), buscando compreender os significados particulares da apropriação do vídeo pelos Kayapó.

$\mathrm{O}$ autor argumenta que o ato de filmagem e o processo de edição adquirem extrema importância política e social, mobilizando valores da sociedade kayapó:

\begin{abstract}
Among the Kayapo, for example, becoming a video cameraperson, and even more importantly, a video editor, has meant combining a prestigious role within the community with a culturally and politically important form of mediation of relations with western society. As a combination of the two main prerequisites for political leadership in contemporary Kayapo communities, it has been one way that people have promoted their political careers (TURNER, 1992, p. 7).
\end{abstract}

Turner aponta aqui para a importância de considerarmos o processo de produção das imagens e seus resultados em uma dinâmica comunitária. Para o autor, questões como "para quem entregar a câmera?" ou "o que filmar?" podem ser reveladoras de sentidos culturais mais complexos.

A primeira questão parece ter relação com o tema das prerrogativas rituais, assunto que figura de forma abundante na literatura disponível sobre os Mebêngôkre (explorado profundamente por Lea, 1986; mas também presente em Turner, 1966; Vidal, 1977; Gordon, 2006). Diferente dos bens cerimoniais, utilizados no ritual para marcar distinção, o uso da câmera não é exatamente um direito 
DIEGO MADI DIAS e ANDRÉ DEMARCHI - A imagem cronicamente imperfeita...

transmitido por parentesco. A escolha dos cinegrafistas, assunto público por excelência, segue o modelo de obtenção de consenso através das reuniões na casa dos homens. A utilização do equipamento tem relação com a noção de prerrogativa; portanto, na medida em que possibilita a diferenciação, articulando posições hierárquicas (especialmente etárias), e se baseia em permissão.

Quanto ao problema colocado em seguida ("o que filmar?"), se tomarmos o ato de filmagem em dois níveis - conteúdo e performance , podemos concluir, com Turner, que a ação de filmar adquire para o grupo um sentido de evento e apresentação ainda mais importante que o produto fílmico em si.

Turner descreve o uso kayapó do vídeo como uma maneira de filmar "the same events being filmed by representatives of the national and international media" (TURNER, 1992, p. 7). Mais do que mera documentação dos encontros políticos entre os Kayapó e a sociedade nacional, a filmagem feita pelos índios significou um modo de sugerir semelhança, deslocando a problemática para o fato de que 'há um índio filmando'.

O discurso de Mokuká, proferido na ocasião do RAl's Third International Festival of Ethnographic Film, é ilustrativo nesse sentido. Vejamos o trecho a seguir:

Do whites alone have the understanding to be able to operate this equipment? Not at all! We Kayapo, all of us, have the intelligence. We all have the hands, the eyes, the heads that it takes to do this work (MOKUKÁ KAYAPÓ apud TURNER, 1992, p. 8).

Neste sentido, o trabalho de Turner sobre o uso de vídeo entre os Kayapó não nos autoriza ao exame do material filmado pelos indígenas através da interpretação dessas imagens, considerando a presença de um suposto valor intrínseco - estético ou referencial. Ao contrário, o entendimento da apropriação dos recursos audiovisuais, conforme executada pelos Kayapó, deve se dedicar às especificidades do contexto de produção das imagens, considerando tanto as intencionalidades que estão em jogo quanto os agenciamentos acionados pela câmera.

A pesquisa com vídeo entre os Kayapó coloca a necessidade de atentarmos não exatamente para os filmes que são feitos, mas para 
DIEGO MADI DIAS e ANDRÉ DEMARCHI - A imagem cronicamente imperfeita...

aquilo que é feito quando se está filmando. O discurso de Mokuká, na medida em que nos remete a uma relação entre corpo e técnica, permitirá a reelaboração de nossas preocupações: trata-se de entender o que é feito com o corpo por meio de sua relação com a câmera.

\section{Câmera-corpo}

As discussões sobre corporalidade se desenvolvem, no interior da etnologia sulamericana, como decorrentes de uma questão colocada por Joanna Overing no simpósio Social Time and Social Space, realizado no Congresso de Americanistas de 1976. Na mesma direção, Seeger, Da Matta e Viveiros de Castro (1979, p. 10) sugerem que "as noções ligadas à corporalidade e construção da pessoa são algo básico". A partir de então, o corpo passa a desempenhar um lugar central como idioma para definir identidade e diferença, objetivando as relações sociais nas terras baixas da América do Sul.

Com o objetivo de empreender uma reflexão acerca da corporalidade, lembremo-nos da anedota vivida pelo missionário e antropólogo Maurice Leenhardt ${ }^{3}$ entre os Kanak, povo indígena da Nova Caledônia, na região da Melanésia. Leenhardt pergunta a Boessou, um índio convertido ao cristianismo, se não teria sido a noção de "alma" aquilo que os ensinamentos missionários trouxeram de novo para sua comunidade. De forma um tanto quanto inesperada, Boessou responde que não, que os Kanaks da Nova Caledônia já conheciam a ideia de espírito/alma, mas que - ao contrário - os missionários haviam trazido a concepção de "corpo".

Revela-se justamente aí a concepção multiculturalista ocidental (VIVEIROS DE CASTRO, 1996), a saber, a consideração de que diferentes representações e usos do corpo consistiriam em variações culturais acerca de uma mesma natureza dada (o corpo). A resposta indígena possibilita pensar a multiplicidade dos corpos. Demonstra, assim, que o antropólogo, como o indígena, baseia-se em crenças - sobre a

\footnotetext{
${ }^{3}$ Recuperada por Tânia Stolze Lima (2002) em $O$ que é um corpo? e também pelo catálogo da exposição Qu'est ce qu'un corps?, ocorrida no Museu do Quai Branly e que procurou apresentar imagens de corpos de diferentes partes do mundo em perspectiva comparada.
}

Espaço Ameríndio, Porto Alegre, v. 7, n. 2, p. 147-171, jul./dez. 2013. 
DIEGO MADI DIAS e ANDRÉ DEMARCHI - A imagem cronicamente imperfeita...

universalidade do corpo, por exemplo (TAYLOR et al, 2006).

Essa brevíssima digressão nos servirá para que possamos sublinhar questões que têm se mostrado cruciais nos estudos de etnologia indígena, seja na Melanésia ou na Amazônia. Em primeiro lugar, tematizar a corporalidade parece mesmo algo inescapável para o entendimento de ontologias amazônicas marcadas por princípios de imanência, fabricação do corpo, consubstancialização, perspectivismo, predação etc (Seeger, Da Matta e Viveiros de Castro, 1979; Viveiros de Castro, 1987 e 1996) ${ }^{4}$. Ainda, devemos estar atentos para o fato de que tomar os corpos no sentido de uma "natureza dada" não trará o rendimento esperado para a análise desses grupos.

Passamos a explorar, em seguida, a relação entre corpo e câmera - com o objetivo de tratar, para o caso estudado, de um uso do vídeo que se mostrará revelador de concepções nativas sobre corporalidade e, por consequência, sobre a noção de sujeito.

O discurso de Mokuká, como vimos, aponta para certo privilégio formal a partir de uma noção de habilidade que o coloca em condição de semelhança com outros realizadores audiovisuais (todos teriam "as mãos necessárias para fazer o trabalho"). Remete, dessa maneira, a uma noção de agência encontrada em Tim Ingold (2000).

Retomando questões já presentes no trabalho de Gregory Bateson, a teoria de Ingold dá centralidade à inteligência corporal e, portanto, à ideia de skill como um modo instrumental de estar no mundo ${ }^{5}$. Sua noção de cultura se refere a um sistema de práticas encorporadas, compartilhadas e relativas a contextos práticos de aprendizado e execução. Habilidade, nesta perspectiva, não é uma propriedade exclusiva do corpo, mas de um campo de relações entre humanos e não humanos.

Essa relação está bem colocada na história sobre o primeiro contato de Mokuká com uma câmera de vídeo, em 1989. Um amigo teria deixado uma câmera com Mokuká no encontro de Altamira - ocasião que congregou diferentes povos indígenas contrários à construção de

\footnotetext{
${ }^{4}$ Uma transposição do modelo perspectivista (VIVEIROS DE CASTRO, 1996) não deverá se dar sem ressalvas. Veremos, a seguir, os limites concernentes ao caso kayapó e àquilo que Cesar Gordon (2006, p. 212) chamou de uma "inflexão perspectivista" do pensamento mebêngôkre.

${ }^{5}$ Tal concepção de sujeito aparece como influência da filosofia de Heidegger. Não se refere a um sujeito abstrato que confere sentido ao mundo exterior, mas de um ser-no-mundo (Dasein) (INGOLD, 2000).
} 
DIEGO MADI DIAS e ANDRÉ DEMARCHI - A imagem cronicamente imperfeita...

hidrelétricas na região do Rio Xingu, em 1989. Em sua narrativa, Mokuká dá ênfase ao fato de que não teve instruções para manipular o equipamento. Conta que desenvolveu inicialmente uma relação experimental com a câmera, até que pudesse "se acostumar" com ela. Por fim, em suas palavras, "minha mente entrou na câmera e a câmera entrou em mim".

A história de Mokuká aponta para um aprendizado que está diretamente ligado a um contexto prático de ação. Aprender, nesse caso, não é um processo de assimilação de códigos, mas o desenvolvimento de uma consciência perceptiva quanto às propriedades do equipamento, um conhecimento tácito necessariamente vinculado à práxis, uma capacidade de se situar em um campo de ação específico e conhecer as possibilidades de agência dadas por aquele meio.

Queremos argumentar que, para o grupo estudado, o ato de filmar supõe uma relação simbiótica entre homem e máquina, uma atividade corporal mais do que uma ação baseada em regras previamente internalizadas. A câmera como extensão do corpo nos conduzirá às formulações deleuzianas sobre o cinema de Dziga Vertov: um cinema sensório-motor (DELEUZE, 1985).

Afastando-nos dos paradigmas da interpretação e da semiose, uma concepção instrumental de sujeito, conforme a que temos em Ingold (2000), pode agora ser percebida no homem perfeito de Dziga Vertov, o homem máquina, que tem suas capacidades perceptivas multiplicadas. A despeito do entusiasmo construtivista ${ }^{6}$, é interessante notar que o juízo estético mebêngôkre sobre a imagem filmada se dará a partir de critérios que encontram correspondência no discurso do construtivismo russo, que concebe o cinema como uma arte mecânica e anônima?.

\footnotetext{
${ }^{6}$ Há mesmo um filme que entitula-se Entusiasmo, produzido por Dizga Vertov em 1931, ou seja, no contexto do programa stalinista de modernização econômica da então URSS. A película trata da progressão histórica que possibilitará o novo homem soviético: "pela poesia da máquina, iremos do cidadão lerdo ao homem elétrico perfeito" (VERTOV, 1983, p. 249).

${ }^{7}$ Não temos o objetivo de enquadrar a prática de vídeo entre os Kayapó em um gênero cinematográfico. Jamais diríamos que o vídeo kayapó é um exemplo do cinema construtivista soviético dos anos de 1920. Isso porque, além dos abismos geográfico e histórico, e apesar de enfatizarmos aqui as aproximações, há certamente muitas diferenças. A primeira se refere ao cinema como arte industrial - não diríamos que os Kayapó compartilham uma exaltação à máquina. Em termos técnicos/estéticos, talvez a maior diferença resida na importância dada pelo construtivismo à montagem como meio de linguagem efetivamente audiovisual (já os Kayapó que conhecemos valorizavam a filmagem como ato fundamental, desprezando a montagem). Por outro lado, as aproximações são instigantes na medida em que possibilitam aceder à
} 
A valorização da forma pelos indígenas, como veremos, acaba por apresentar um sujeito objetivado, ou melhor, esconde o sujeito em sua própria capacidade de repetir a forma, recolocando a questão da autoria nos termos de uma relação ambígua entre subjetividade e objetividade. Também para Dziga Vertov a forma era importante: podia expressar, em detrimento de toda a diferença, uma unidade dada pela câmera. As imagens colhidas pelos diversos kinoks 8 tinham, para Vertov, uma estrutura comum dada pelo modo de funcionamento e operação do equipamento. Uma gramática e uma sintaxe próprias do registro audiovisual produziriam imagens de forma combinada com 0 cinegrafista, estabelecendo um limite para a produção de imagens ao mesmo tempo em que oferecem sua condição de possibilidade.

Também encontramos aqui correspondentes para 0 ideal antinarrativo das imagens kayapó. Para dar conta de uma linguagem essencialmente audiovisual, Vertov empreende verdadeira recusa da literatura e do teatro, respectivamente, da fábula e do drama. Desse modo, o cinema de Vertov não pretende contar histórias sobre o mundo, mas concede centralidade à experiência sensorial objetiva. A seguir, veremos a importância da ação e do movimento na relação que assumem o corpo e a câmera para o caso kayapó.

\section{Imagem e desempenho ${ }^{9}$}

O momento de apreciação das imagens ajuda a compreender a relação estabelecida entre a câmera e o corpo do cinegrafista, indicando um modo de estar nas imagens relacionado à presença do cinegrafista como mediador/produtor. No caso kayapó, a recepção endógena

imagem do ciborgue (HARAWAY, 2009), explorando um potencial agentivo não humano (INGOLD, 2000) e conceituando essas imagens como diretamente relacionadas a um dispositivo sensório-motor (DELEUZE, 1985).

${ }^{8}$ O grupo dos Kinoks foi um coletivo de documentaristas fundado por Vertov em 1919 (XAVIER, 1983).

${ }^{9}$ Uma primeira reflexão acerca da relação entre imagem e desempenho pode ser empreendida a partir dos termos utilizados para designar as atividades de fotografia e filmagem. Foto e filme são igualmente traduzidos por mekaron, palavra que também designa alma/espírito/duplo. A atividade de produção dessas imagens, no entanto, apresenta uma diferença importante: fotografia - mekaron kabá; filmagem - mekaron ipêx. $\mathrm{O}$ ato de tirar fotos, mekaron kabá, remete à ideia de cópia, é também como se referem às cópias de DVDs ou mesmo pode significar "xerox" (de um documento, por exemplo). Filmar, mekaron ipêx, apresenta a dimensão de desempenho da qual nos ocuparemos aqui. Isso porque ipêx está necessariamente ligado ao ato de construir/fazer/desempenhar (fazer uma casa, por exemplo). 
DIEGO MADI DIAS e ANDRÉ DEMARCHI - A imagem cronicamente imperfeita...

remonta justamente ao momento de produção das imagens, sugerindo presença a partir de uma relação de indexicalidade ${ }^{10}$. $O$ entendimento do papel do mediador será possível a partir do estudo do julgamento estético da imagem filmada.

Entre os Kayapó, ser bom cinegrafista não significa necessariamente fazer bons planos, mas sim ser capaz de manter o quadro e a sequência. Queremos dizer que os Kayapó que conhecemos não consideram o material em duas etapas ("material bruto" e "produto acabado"). Ao invés disso, eles gostam de planos-sequência, de maneira que o produto imediato da filmagem está acabado e pronto para visionamento quando a câmera é desligada.

Resumidamente, podemos dizer que apreciam a continuidade. Terence Turner (1992) já havia caracterizado a importância do processo e da sequência para a edição de imagens entre os Kayapó ${ }^{11}$ :

In Kayapo thought, replication of originally 'natural' forms through concerted social action is the essence of the production of human society. It is what 'culture' consists of. The perfection of such socialized forms through repeated performance embodies the supreme Kayapo value, at once social, moral and aesthetic, of 'beauty'. Note that 'beauty', in this sense, comprises a principle of sequential organization (...). This is what Tamok's video of the ceremony also does. He faithfully shows every repetition of every performance, each with its successive increments of regalia and participants. His video replicates, in its own structure, the replicative structure of the ceremony itself, and thus itself creates 'beauty' in the Kayapo sense (TURNER, 1992, p. 9).

Tanto a experiência de Terence Turner, no que diz respeito ao projeto de vídeo entre os Kayapó, quanto a nossa própria experiência revelam a edição e a montagem de imagens como atividades não exatamente rejeitadas pelos Kayapó, mas desnecessárias.

\footnotetext{
${ }^{10}$ A imagem é índice da conjuntura espaço-temporal filmada e, portanto, da presença do cinegrafista. Como índice, a imagem mantém relação direta de causalidade com o momento de produção (a imagem existe porque houve a filmagem). O conceito de índice é importante por ressaltar um fluxo de causalidade, apontando para a causa, conectando duas instâncias de algo que existe em relação. Não se refere àquilo que lhe deu origem por associação de semelhança (ícone) ou por abstração/convenção (símbolo), mas por contiguidade - constitui a natureza daquilo a que se refere. Sobre a tríade peirceana (ícone, índice, símbolo), ver: Peirce (2000).

${ }^{11}$ Cesar Gordon (2009) ressalta também a importância de uma concepção processual para o entendimento do critério de atribuição de beleza entre os índios Xikrin (subgrupo Mebêngôkre).
}

Espaço Ameríndio, Porto Alegre, v. 7, n. 2, p. 147-171, jul./dez. 2013. 
DIEGO MADI DIAS e ANDRÉ DEMARCHI - A imagem cronicamente imperfeita...

Queremos argumentar, portanto, que a beleza não está exatamente na imagem, mas em como ela foi filmada. Não raro, ao assistirem a um vídeo, desejam saber quem foi o cinegrafista. Por isso, sugerimos que esta é também uma forma de estar através da imagem uma vez que a mão do mediador permanece presente, compondo o produto final sobre o qual recairá o julgamento estético.

Há, portanto, como decorrente do exposto, uma constante descrença quanto à capacidade da imagem em substituir a realidade, não deixando que se apague a mão do mediador. Para um Kayapó, a imagem jamais poderá ser a realidade e, como produto de uma relação com o mundo, o que deve ser julgado é justamente a condição de produção - o que tem a ver com a capacidade de quem filma.

A reclamação recorrente se dá quando o cinegrafista "treme" (não mantém bem o quadro e/ou a sequência). $O$ julgamento estético não recai sobre o fim (filme, em seu aspecto de unidade e coesão interna), mas sobre o processo que deu origem a ele. A beleza está ligada à questão do desempenho.

A ênfase que temos aqui na etapa de produção, e a consequente valorização do papel do mediador/realizador, difere do lugar conferido ao "autor" no cinema. Não diríamos, assim, que o julgamento acerca do desempenho do cinegrafista, entre os Kayapó, segue as mesmas motivações autorais que temos no cinema. Em outras palavras, diferente do que temos no "nosso" cinema, a valorização da dimensão de realização aqui não pode ser traduzida em uma valorização de aspectos ligados à pessoalidade e/ou criatividade pessoal (para "nós", o que caracteriza - por excelência - a autoria). Trata-se, muito mais, de valorizar o êxito no cumprimento de aspectos formais a serem seguidos, algo parecido com o que temos na descrição de Alfred Gell sobre o escultor de madeira das ilhas Trobriand:

Consideremos a posição de um escultor nativo das Ilhas Trobriand, encarregado de acrescentar mais uma peça ao corpus de tábuas de proa já existente. (...) Pode-se supor que ele deve exercitar a faculdade do julgamento estético, mas não é como isso realmente aparece ao artista das Ilhas Trobriand, que esculpe dentro de um contexto cultural no qual a originalidade não é valorizada por si mesma, e de quem é esperado, tanto por seu público quanto por ele mesmo, que siga um 
DIEGO MADI DIAS e ANDRÉ DEMARCHI - A imagem cronicamente imperfeita...

modelo ideal de tábua de proa (...). O escultor de Trobriand não se dispõe a criar um novo tipo de tábua de proa, e sim um novo emblema de um tipo existente. (...) Talvez a analogia mais próxima, em nossa cultura, seja a de um músico tecnicamente preparado para oferecer a interpretação perfeita de uma composição já existente, como, por exemplo, a 'Sonata ao luar' (GELL, 2005, p. 54-55).

A importância do processo, no entanto, deve ser mais bem caracterizada quanto às diferentes possibilidades de valorização processual da forma ou do conteúdo. Tomando como exemplo a filmagem de um ritual, não nos parece que a preocupação estética tem a ver com o processo do conteúdo filmado (o ritual em si), mas aponta para um virtuosismo do cinegrafista na execução de sua atividade.

Temos aqui algo que aparece de modo um pouco diferente daquilo que foi notado por Terence Turner com relação à experiência do The Kayapo Video Project. Nunca ouvimos a reclamação de que "falta uma parte" da dança ou do ritual, mesmo que em alguns momentos tenha havido cortes claros que não permitiram a cobertura completa. Talvez a diferença ocorra pelo fato de que Turner analisava o trabalho de edição, enquanto o interesse aqui recai na produção de imagens e no julgamento relativo à primeira recepção pela comunidade.

Terence Turner fala de um gosto pelo processo no sentido de que seria importante estarem contempladas todas as etapas. Nós nunca ouvimos a reclamação de que "falta uma parte", ainda quando a falta tenha se mostrado óbvia. A reclamação é invariavelmente a de que "o cinegrafista treme". O processo valorizado, então, é o processo da forma e não do conteúdo. Os índios, eventualmente, reclamam quando falta uma parte da festa ou do ritual filmado, podem querer ver tudo e até ficar chateados se isso não for possível. O que importa, porém, e que é preciso destacar aqui, é que essa falta não aparece como critério acionado para o julgamento do que vem a ser uma boa imagem. A imagem bela ( $m e j x$ ) está necessariamente ligada ao desempenho e é, então, equivalente à imagem que "não treme".

Não queremos sugerir que eles de nenhum modo apreciem a ideia da edição. Alguns vídeos apresentavam cortes, ainda que não houvesse o uso da montagem como recurso de construção narrativa. A edição não 
DIEGO MADI DIAS e ANDRÉ DEMARCHI - A imagem cronicamente imperfeita...

é exatamente um problema, mas é antes desnecessária - uma vez que o julgamento estético está ligado justamente ao processo de captação de imagens (como a imagem foi feita) e não a uma etapa de pós-produção. Por outro lado, o processo de edição tem aparecido como algo cada vez mais valorizado no contexto dos "projetos". Há, hoje, em um nível maior do que tínhamos no contexto encontrado por Terence Turner, pessoas que dão algum valor ao processo de edição, querendo aprender a técnica. No entanto, tal valorização apareceu ligada a uma expectativa em corresponder a demandas externas. Essas pessoas são participantes de "projetos" e percebem a necessidade de um formato, entendendo que o vídeo editado corresponde melhor como 'produto' para a circulação em outras redes (no mundo dos kuben [brancos], principalmente). O que importa aqui é mais uma dinâmica pretendida de distribuição, numa perspectiva dialógica, do que propriamente um julgamento estético acerca do produto fílmico. A edição é, então, muito mais um processo de adequação de meios aos fins - não interessando para efeito de julgamento da imagem bela (nos termos mebêngôkre), que, como vimos, corresponde à imagem bem executada.

Por fim, é preciso salientar também que há certamente imagens que evidenciam um valor referencial, como os encontros políticos notáveis. As pessoas assistem a estes vídeos, efetivamente, para ter acesso ao conteúdo e, nesses casos, a atenção está mais voltada para a realidade trazida na tela. São casos que parecem ser tratados pelos Kayapó como meros registros documentais, onde realmente o conteúdo importa mais que a forma, mas onde também provavelmente não faça tanto sentido falar em apreciação estética. O vídeo da índia Tuíra, que em 1989 encostou seu facão no rosto de um engenheiro da Eletrobrás, é um dos preferidos. No entanto, ao assistir a esse vídeo, os Kayapó estão muito mais animados com os acontecimentos do que preocupados em avaliar a qualidade da imagem ${ }^{12}$. Esses casos de filmagem no contexto de encontros políticos com a sociedade nacional são recorrentes e ajudarão a dar continuidade à reflexão.

\footnotetext{
12 Mesmo quando esses vídeos são realizados por indígenas kayapó, como é o caso de um vídeo sobre o encontro de Altamira, em 1989, que circula por diversas aldeias.
} 
DIEGO MADI DIAS e ANDRÉ DEMARCHI - A imagem cronicamente imperfeita...

\section{Àkti e a origem da bravura}

Vimos que o julgamento das imagens filmadas está diretamente relacionado com o desempenho do cinegrafista. Desse modo, a reclamação de que uma imagem não está boa (punure) pode ser entendida como julgamento à condição do corpo que a realizou: um corpo mole, fraco (rerekre). Ao contrário, uma imagem bonita, realizada de forma correta ( $m e j x)$, corresponderia a um corpo rígido, forte (töjx).

A ligação entre corpo e imagem, conforme vimos a partir do juízo estético sobre a imagem filmada, sugere que tenhamos simultaneamente uma imagem bela ( $m e j x)$ e um corpo rígido (töjx) - em oposição ao par $<<$ imagem ruim (punure) / corpo fraco (rerekre) $>>$. Tal relação entre corpo e imagem se sustenta em um conceito de beleza que, conforme demonstrado pela literatura mebêngôkre, deve ser tomado em uma perspectiva abrangente - indicando tanto coisas e pessoas belas quanto sentidos moral e eticamente corretos:

A palavra [mejx] qualifica tanto coisas físicas (objetos e corpos) quanto imateriais (nomes e pessoas), por exemplo. Mejx também não exprime somente valores estéticos, senão igualmente valores morais ou éticos. 0 campo semântico da palavra cobre uma série de atributos que poderíamos glosar como 'bom, bem, belo, bonito, correto, perfeito, ótimo'. Além disso, mejx pode ser contraposto, dependendo do contexto de enunciação, aos seguintes termos antonímicos: punure ('ruim, feio, mau, errado'); e kajkrit ('comum, ordinário, vulgar, trivial'), ou simplesmente mejx kêt (onde kêt $\approx$ partícula de negação) (GORDON, 2009, p. 7-8).

O gosto por uma imagem bonita/correta poderá dizer sobre uma postura corporal desejável e mesmo necessária à execução da atividade de filmagem. $O$ trabalho do cinegrafista, em alguma medida ${ }^{3}$, pode então ser comparado a tantas outras atividades relacionadas ao desempenho do corpo: o ataque à casa de marimbondos, o pernoite nas

\footnotetext{
13 Ser cinegrafista significa muitas coisas entre os Kayapó. Trata-se de uma prática que, além de mobilizar conceitos nativos (que desenvolvemos aqui), parece efetivamente colocar novas questões (especialmente no que tange ao contato interétnico). Não desejamos sugerir, portanto, que toda a atividade deve ser entendida a partir de uma sócio-cosmológica prévia. De forma a delimitar objetivos atuais, buscamos extrair rendimentos que estejam ligados ao regime sócio-cosmológico, seguindo a pista deixada pela análise da recepção endógena e procurando dar conta de uma relação entre corpo e imagem.
}

Espaço Ameríndio, Porto Alegre, v. 7, n. 2, p. 147-171, jul./dez. 2013. 
DIEGO MADI DIAS e ANDRÉ DEMARCHI - A imagem cronicamente imperfeita...

águas de um rio, a realização de pequenas queimaduras na pele etc. São situações em que se deve demonstrar um corpo forte.

Ainda mais interessante será a contextualização dessa prática na ocasião dos encontros políticos entre os Kayapó e os representantes do governo regional/nacional. Foi justamente nessa situação em que Terence Turner notou a capacidade dos índios em se fazer presente através do ato da filmagem. Cesar Gordon (2006, p. 209-210) chamou a atenção para o fato de os índios Kayapó serem tão conhecidos pela presença e, ainda mais, pelo exercício de sua bravura em situações notáveis de contato político com a frente de expansão brasileira, mesmo após o processo de pacificação. O célebre encontro de Altamira, ocorrido em 1989, permanece como exemplo clássico dessa relação entre índios e brancos, marcada por hostilidade, tendo sido descrito por Turner como o equivalente simbólico a uma caçada coletiva (TURNER, 1991, p. 337).

Conforme notou Gordon, nessas reuniões fora da aldeia, os índios se preparam diferente de como normalmente vão à cidade. Em situações cotidianas, utilizam roupas de branco, procurando demonstrar civilidade; procuram se apresentar de modo domesticado ou pacífico (uabô ou djuabô). Nas situações de encontro político, então, os "guerreiros" assumem uma postura selvagem ou feroz (àkrê ou djàkrê), tratando da relação com o estrangeiro a partir da lógica da guerra e da predação. Vejamos a descrição desses diferentes estados do ser, conforme apresentada por Gordon:

A vida mebêngôkre (...) depende de um equilíbrio entre esses dois estados ou qualidades. Por isso mesmo, eles não podem ser igualmente distribuídos entre as pessoas. Mulheres, no geral, devem ser mais uabô; homens, mais àkrê; chefes precisam ser àkrê, mas devem, ao mesmo tempo, exercer a generosidade, aprendendo a ouvir e ponderar; feiticeiros e xamãs também são àkrê e assim por diante. $\mathrm{E}$ essas características são efetivamente produzidas nas pessoas, mediante uma série de procedimentos controlados de transformação 'afeto-corporal', a que são submetidas desde crianças, e que incluem: ingestão de certos alimentos, ordálios e provas de fogo (no caso da qualidade agressiva); desenvolvimento da audição, do entendimento e do respeito/vergonha (pia'àm), enfim, de uma moralidade comunitária (no 
DIEGO MADI DIAS e ANDRÉ DEMARCHI - A imagem cronicamente imperfeita...

caso da qualidade domesticada ou mansa) (GORDON, 2006, p. 218).

A tentativa aqui tem sido, justamente, a de relacionar o ato da filmagem com as provas de fogo. Talvez se diferenciem no sentido de que as provas atuam na produção do corpo, enquanto que a filmagem pode também revelar a qualidade deste corpo construído. Cumpre, pois, destacar o caráter ambivalente da filmagem no que diz respeito à produção do corpo: não apenas dá visibilidade à condição corporal mas também constitui esse corpo, contínua e indefinidamente, para a produção de imagens cada vez mais belas (o que pode ser notado a partir da evolução dos cinegrafistas). Como pretendemos demonstrar, no entanto, a impossibilidade da imagem perfeita sugere um processo sempre inacabado.

Vale ressaltar que, para o entendimento dos usos da imagem pelos Kayapó, é fundamental a dimensão de relacionamento com a alteridade, conforme notado por Turner desde sua descrição pioneira do trabalho com vídeo entre esse grupo. Desejamos propor um lugar para o vídeo no interior deste quadro de encontro político com a sociedade regional/nacional que possa ajudar a pensar a filmagem como uma forma de constituição da subjetividade àkrê e a consequente objetificação do outro. Uma prática que opera justamente a passagem de objeto a sujeito e que, portanto, mobiliza essas diferentes qualidades do ser kayapó, estabelecendo, respectivamente via bravura e mansidão, os pares nós/sujeito $X$ eles/objeto em uma relação assimétrica.

Reside aqui o que Cesar Gordon (2006, p. 218) chamou de "uma inflexão perspectivista do pensamento mebêngôkre", algo relacionado à alternância entre "dois vetores da relação" com a alteridade e tão bem expresso pelo mito de Àkti, que conta a origem da bravura:

Antigamente os índios eram mansos, fracos e não tinham armas. Eles viviam a mercê de Àkti, o gavião gigante, que os caçava, carregava-os pelo céu até seu ninho e os devorava. Um dia uma mulher velha foi ao mato com seus dois sobrinhos (netos) pequenos para tirar palmito. Ali ela foi atacada por Àkti diante dos meninos, que fugiram aterrorizados para a aldeia. O pai (ou tio) dos meninos (irmão da mulher devorada pelo grande gavião), movido pelo sentimento de vingança, descobre um meio de liquidar o monstro, 
DIEGO MADI DIAS e ANDRÉ DEMARCHI - A imagem cronicamente imperfeita...

transformando seus sobrinhos em super-homens. Ele coloca os meninos dentro de um grotão, alimentandoos com beiju, banana e tubérculos para que cresçam bastante e fiquem fortes. Passam-se os dias e é como se os meninos fermentassem dentro d'água. Depois de um tempo eles haviam crescido e se tornado enormes, mais fortes e capazes que qualquer índio. Caçavam antas e outras caças grandes como se elas fossem pequenos roedores. Um dia, então, Kukry-uire e KukryKakrô saem para caçar Àkti munidos de borduna, lança e um apito de taquara, armas feitas pelo tio. Ergueram um abrigo de palha no chão, de onde se via o ninho do gavião. Ao pé da árvore havia uma pilha de restos humanos como ossos e cabelos. Os irmãos atraíram Àkti soprando o apito. A imensa ave descia pronta para o ataque, mas eles escondiam-se no abrigo, deixando-a desnorteada. Fizeram assim muitas vezes, deixando o pássaro cada vez mais furioso e desorientado, até que mostrou sinais de cansaço. Os irmãos, então mataramno com lança e borduna. Como troféu tiraram as penas de $\dot{A} k t i$ e puseram na cabeça. Cantaram. Celebraram. Depois depenaram a ave e retalharam-na em pedaços pequenos. Sopraram as penas e elas foram transformando-se em pássaro. As penas maiores deram origem às aves maiores (gavião, urubu, arara) as plumas menores deram aos pequenos pássaros como o beija-flor (GORDON, 2006, p. 213-214).

Gordon passa a examinar a relação entre o mito de Àkti e o mito da origem do fogo, que teria sido roubado da onça (LÉVI-STRAUSS, 1964). "Ambos tematizam ideias mebêngôkre sobre a importância de predar e não ser predado (ser o predador, e não a presa)" (GORDON, 2006, p. 216). O autor segue destacando, no contexto dos encontros políticos, a importância do "falar duro", para "fazer com que os brancos tenham medo".

A atividade do cinegrafista, por definição, é uma atividade dialógica, que mobiliza um encontro com a alteridade. Esse encontro, por sua vez, não pode prescindir do jogo relacional entre objeto e sujeito - posições não marcadas, não absolutas, mas contextuais. O que está em questão, portanto, é justamente um modo de marcar essas posições e de se fazer sujeito frente ao outro através da filmagem. A câmera como recurso dialógico, que opera uma passagem de objeto para sujeito, só pode ser conduzida por um corpo duro, um corpo firme. Isso porque a qualidade djàkrê é aquela que importa para o

Espaço Ameríndio, Porto Alegre, v. 7, n. 2, p. 147-171, jul./dez. 2013. 
DIEGO MADI DIAS e ANDRÉ DEMARCHI - A imagem cronicamente imperfeita...

relacionamento com a alteridade. "É a qualidade da 'alter-objetificação' e da 'auto-subjetificação"(GORDON, 2006, p. 218). Neste sentido, é preciso olhar mais de perto para a forma como é produzido esse corpo e em que momentos, para além da filmagem, seu endurecimento é acionado como condição de possibilidade da beleza.

\section{Beleza e endurecimento}

Algumas das passagens do mito de Àkti podem ser aqui retomadas para melhor explicitar os termos que embasam o juízo estético kayapó; a saber, as relações entre a beleza dos corpos e sua rigidez, ou seja, entre endurecimento e embelezamento. Isto porque, para além de evidenciar a "inflexão perspectivista" enunciada por Gordon, este mito reencena um processo corporal feito e refeito pelas mães e avós em seus filhos durante a infância, visando a um momento ápice em que o corpo, depois de longamente produzido, deve ser testado ${ }^{14}$.

Este momento ocorre quando dos rituais de nominação, onde as crianças que receberão cerimonialmente os nomes são adornadas com penas, plumas, cocares, colares de dentes, braceletes, braçadeiras, pulseiras, colares de miçangas, máscaras, dentre outros adereços, geralmente adquiridos, roubados e produzidos através de relações com outros, inimigos, seres animais, vegetais, sobrenaturais, espíritos, enfim, não humanos. O ritual representa o grau máximo da beleza kayapó, porque é também o momento de afirmação dessas agências não humanas (GORDON, 2006). Não apenas dos nomes, mas de toda a parafernália cerimonial, de tudo aquilo que é pensado como apropriação de outrem e que faz sua aparição no ritual. Neste contexto eles estão novamente reconectados aos seus donos originais e, por isso, tornamse verdadeiramente bonitos.

Nesta ocasião, onde para se tornar humano é necessário se desumanizar, o corpo deve estar protegido, deve ter sido antes preparado e testado para estar ali. O processo de preparação desse corpo se inicia com o nascimento, através da primeira pintura de

${ }^{14}$ Essas ideias estão mais amplamente desenvolvidas em Demarchi (2010). 
DIEGO MADI DIAS e ANDRÉ DEMARCHI - A imagem cronicamente imperfeita...

urucum e das massagens na cabeça que o recém-nascido recebe quando vem ao mundo. Dali em diante, até o momento em que será nomeada, a criança é submetida a um longo tratamento que, além das dietas alimentares, inclui a aplicação de sucessivas camadas das tinturas de urucum e jenipapo para fortalecer, embelezar a pele e endurecer o corpo; e o uso cotidiano de faixas de tecido de algodão costurados pelas mães, tingidos de urucum e colocados um pouco abaixo das articulações das pernas e um pouco acima das articulações dos braços, também com o intuito de fortalecer o local onde serão depositados, no ritual, os pesados, grandes e perigosos braceletes e braçadeiras de miçanga15. Além disso, como que para ir testando paulatinamente os corpos das crianças, as mães as submetem, de oito em oito dias, a uma pesada ornamentação, prerrogativa a que só as crianças têm direito. Cohn (2009, p. 25) interpreta este fato como uma "forma de afirmar e reafirmar continuamente" a identidade social da criança, de modo a fazer conhecer aos demais membros da comunidade seus bens cerimoniais. Acreditamos que se trata também de ir testando o corpo da criança até o momento em que dele será exigido o máximo, o que não exclui a possibilidade de ser um modo de conceder visualidade às suas prerrogativas rituais. O que estaria em jogo, então, não seria apenas a afirmação da identidade da criança, mas a afirmação e reafirmação contínua do próprio fato de que o corpo da criança suporta os bens cerimoniais e os suportará por ocasião do ritual de nominação.

Todos estes procedimentos corporais visam, por um lado, à produção do parentesco através da corporalidade (COHN, 2009) e, por outro, à produção do corpo para o ritual. Visa a produzir o "ator social ordinário", o "parente", mas também o "agente", aquele que pode se transformar no ritual (TURNER, 1995; COELHO DE SOUZA, 2002; GORDON, 2006).

Parece-nos que é justamente este último processo que está evidenciado no mito de Àkti. Para se tornarem "agentes", os heróis (que no mito são meninos) recebem uma dieta especial a base de bananas, beiju e tubérculos. Em outra versão desta narrativa, coletada por Vidal

\footnotetext{
${ }^{15}$ Considerando que a miçanga é um bem cerimonial com alta carga de beleza e alteridade, sugiro que sua utilização pela criança demanda uma preparação específica justo na região onde eles serão postos. A miçanga tem considerável valor para os kayapó e é considerado um importante item a ser constantemente adquirido dos brancos. Daí, suspeitamos, vem tanto sua beleza quanto seu perigo (DEMARCHI, 2009).
} 
DIEGO MADI DIAS e ANDRÉ DEMARCHI - A imagem cronicamente imperfeita...

(1977, p. 225), pode-se ler que, além da dieta, os corpos dos garotos foram submetidos a um tratamento com urucum e coco, depois de serem limpos "da sujeira e do melado do peixe" com talhas de palmeiras. Essa preparação do corpo visa ao seu aumento e ao seu fortalecimento para um momento especial de enfrentamento com o inimigo. O interessante é que não só a preparação, mas o próprio rito está contido no mito. Depois de matarem o grande gavião, os heróis roubam-Ihe as penas, dançam e celebram. Apoderam-se da beleza do inimigo e rapidamente a colocam para funcionar no sistema cerimonial kayapó. A partir daquele momento, somente os heróis poderão usar no ritual as penas roubadas de Àkti ${ }^{16}$. O ritual se torna um momento importante para os Kayapó quando notamos que

\begin{abstract}
essa 'animalização ritual' visa no fim das contas à distinção entre humanos (mebêngôkre) e animais, e entre mebêngôkre e kuben - afinal o ritual está ali para contar como, justamente, os animais (e kuben) foram os 'donos' desses itens no tempo pretérito, tendo-os perdido para os Mebêngôkre, seus 'donos' no tempo presente (GORDON, 2006, p. 323, grifo do autor).
\end{abstract}

Para suportar essa carga de alteridade, e sua atualização neste momento específico, é preciso que o corpo tenha sido longamente endurecido para que possa alcançar o ápice da beleza kayapó - que é caracterizada por um corpo duro e rígido, enfeitado com as coisas que foram do outro. Não só o corpo belo deve ser duro, mas seu endurecimento é pré-requisito para que a beleza aconteça e em determinados momentos encontre o seu ápice.

Voltemos à relação entre a câmera e o corpo dos cinegrafistas. Para que sejam belas, as imagens devem ser produzidas, ou talvez suportadas, por um corpo duro. O cinegrafista deve ser capaz de assimilar a agência da câmera, anexando ao próprio corpo as capacidades técnicas do equipamento. Temos aqui uma oportunidade de pensar uma prática em suas dimensões de permanência e variação:

\footnotetext{
${ }^{16}$ Grande parte dos bens capturados pelos Kayapó são considerados belos pela sua carga de distitinvidade, de exclusividade, que faz do dono o único possuidor e possivelmente transmissor dessa "riqueza". O trabalho de César Gordon (2006) busca elucidar como o constante contato com a sociedade envolvente, e a cada vez maior absorção das mercadorias, faz com que haja uma perda de sua distintividade, ocasionado justamente por sua maior circulação entre um número cada vez mais crescente de indivíduos.
}

Espaço Ameríndio, Porto Alegre, v. 7, n. 2, p. 147-171, jul./dez. 2013. 
se, por um lado, como tentamos demonstrar até aqui, os corpos passam por um processo social de endurecimento/embelezamento (e esse processo é importante para a relação com a câmera); por outro lado, a câmera impõe ao cinegrafista um modo de corporalidade, proporcionando mesmo a reelaboração das técnicas corporais (MAUSS, 2003, p. 399-422). A estética do ciborgue (HARAWAY, 2009) parece ser útil ao sugerir acoplamento, ou seja, adição de agentividades ao corpo através de conexões entre matérias heterogêneas e que determinam corporalidades específicas. A especificidade aqui reside na construção de uma capacidade visual que está baseada em todo o corpo (e não em um órgão específico, o olho). Isso porque, para atingir um parâmetro de perfeição dado pelo olho, todo o corpo deve estar engajado na ação de filmagem. A ênfase na ação é importante, pois é justamente o movimento que permite a avaliação estética do corpo através da imagem 17. Em uma linguagem cinematográfica, os Kayapó têm no travelling a possibilidade de executar juízo sobre a imagem e, portanto, sobre o corpo que a produziu. Os termos que embasam o julgamento kayapó sobre o vídeo são tanto a rigidez da imagem quanto seu movimento. O quadro deve, então, não tremer e se movimentar. Podemos entender, assim, a recusa pelo uso do tripé. Embora tenhamos ensinado, nas oficinas, o seu manuseio, os alunos preferiam, explicitamente, trabalhar com a câmera na mão, transferindo para o corpo a tarefa e a capacidade do objeto técnico. Axuapé, um dos melhores cinegrafistas, chegou a ser apelidado de Axuapé-mão-detripé.

O travelling parece-nos o momento ideal para a percepção da permanência de uma sociocosmologia centrada na produção do corpo e, ao mesmo tempo, da variação evocada pela prática de filmagem, que coloca novas possibilidades sensório-motoras e, como veremos a seguir, novos limites.

\footnotetext{
${ }^{17}$ Consideramos, certamente, a dimensão temporal envolvida no julgamento. Quanto maior a duração de um plano, mais difícil será manter o corpo-câmera em movimento rígido. No entanto, essa percepção do tempo estará necessariamente subjugada ao movimento, pois é a dispersão do movimento no tempo que será apreciado. Não se trata, portanto, de um tempo puro - caracterizado por Deleuze (1990) como um tempo livre da ação e do movimento.
} 
DIEGO MADI DIAS e ANDRÉ DEMARCHI - A imagem cronicamente imperfeita...

\section{A imagem cronicamente imperfeita}

Chegamos à conclusão de que a imagem bela terá sido necessariamente produzida por um corpo duro. A relação entre rigidez e beleza, ou seja, entre endurecimento e embelezamento (para destacar a importante dimensão processual), encontra sentido na hipótese que privilegia uma dimensão de eficácia no processo de enrijecimento do corpo e preparação desse corpo para encarnar/suportar a alteridade de maneira plena, no ritual. Estabelecemos, assim, uma classe semântica ampla, que reúne na condição de sujeito as ideias de bravura (àkrê), rigidez (töjx) e beleza (mejx).

É curioso notar aqui a dupla face que assume a relação câmeracorpo na constituição da subjetividade kayapó: ainda que a câmera atue na passagem de objeto a sujeito em uma relação assimétrica, constituindo uma maneira de se tornar agente, a imagem bela tem como ideal de perfeição a dessubjetivação. Isso porque a imagem perfeita, nunca tremida, não valoriza autoria e criatividade pessoal, mas está baseada, como vimos acima, em um virtuosismo na execução da tarefa, colocando em cena um sujeito indeterminado ou, justamente, tirando esse sujeito de cena.

Resta dizer que a imagem bela permanece cronicamente como uma imagem ideal, impossível de ser realizada. A impossibilidade da perfeição continuará falando de dinâmicas comunitárias próprias aos Jê e aos Kayapó, mobilizando agora a relação de distinção e hierarquia etárias ${ }^{18}$. Algumas pessoas mais velhas eventualmente possuem uma câmera e, com ela, realizam procedimentos de filmagem. Invariavelmente, porém, o uso das câmeras do Museu do Índio se deu por jovens escolhidos pelo conselho de homens para participar do "projeto". O mesmo acontece para a participação em diferentes iniciativas e para o uso de diferentes recursos provenientes dos "projetos". Em primeiro lugar, destacaríamos a lógica nativa a partir da qual talvez não faça sentido submeter um velho ao processo de aprendizado que ocorre no contexto de um projeto. Aprender é, por

\footnotetext{
18 Diferenciamos aqui, através das categorias “jovens" e "velhos", dois grupos etários presentes no interior de uma mesma classe de idade, a dos mekrare, "aqueles que já possuem filhos". Para mais informações sobre ciclo de vida entre os Mebêngôkre, ver Gordon (2006, p. 316-321).
} 
DIEGO MADI DIAS e ANDRÉ DEMARCHI - A imagem cronicamente imperfeita...

excelência, algo que diz respeito aos mais jovens. São também os mais indicados para participar de atividades que pressupõem o aprendizado de técnicas dos brancos, principalmente por dominarem melhor a língua portuguesa.

É preciso, então, diferenciar os usos da câmera realizados pelas diferentes faixas etárias. Os mais velhos parecem exibir um objeto de consumo diferenciado a que tiveram acesso por meio de suas relações particulares, evidenciando uma lógica consequentemente mais pessoalizada. Os mais jovens são os escolhidos para a participação nos "projetos", designados pela comunidade para o acesso a recursos disponíveis a partir do contato com os brancos, assunto definitivamente público.

O que acontece quando essas imagens, provenientes dos "projetos", que dizem respeito a toda a comunidade e que são frequentemente exibidas em sessões noturnas, são avaliadas por um público interno? Deparamo-nos aqui com um ciclo vicioso que não permitirá a execução da beleza plena.

Isso ocorre porque, como vimos, a imagem bela deverá estar ligada ao desempenho de um corpo duro - que, em sua rigidez, revela a condição de sujeito/beleza/bravura. Acontece que os jovens jamais poderão ser tão bons guerreiros quanto os velhos. Estes tiveram seu corpo endurecido ao longo de um período maior de vida, enquanto aqueles ainda estão aprendendo (GORDON, 2006, p. 320). A afirmativa pode ser confirmada pelo próprio uso da palavra "guerreiro". A princípio, ela se aplica a todos os homens, tanto que o ngà, espaço que ocupa o pátio central da aldeia e classicamente traduzido pela literatura como a "casa dos homens", é quase sempre proferido pelos índios como a "casa dos guerreiros". No contexto de divisão e comparação etária, como nos casos de divisão de alimentos, a palavra tem seu uso reservado aos mais velhos, com a formação de dois grupos: "os guerreiros" e "os jovens". Dizer que os mais velhos são mais guerreiros significa dizer que são também mais bravos/fortes. E que seu corpo é mais duro.

A dinâmica descrita pode ser entendida a partir de formulações, já clássicas sobre as sociedades Jê, que destacam sua complexidade sociocosmológica e enfatizam o detalhe, a distinção e a hierarquia 
DIEGO MADI DIAS e ANDRÉ DEMARCHI - A imagem cronicamente imperfeita...

(NIMUENDAJU, 1946; LÉVI-STRAUSS, 1956 [2009]; DA MATTA, 1976; CARNEIRO DA CUNHA, 1978; MAYBURY-LEWIS, 1979). Tal dinâmica impede que tenhamos uma sessão de visionamento sem as críticas detalhistas dos mais velhos sobre as imagens filmadas pelos jovens. A imagem sempre estará ruim, entenda-se, tremida. Em alguns momentos, a sessão de visionamento parece mesmo um jogo de encontrar defeitos, através do qual se exerce a diferenciação e a hierarquia. Aí reside, muitas vezes, a maior diversão dos Kayapó: assistir a uma imagem que enfatiza a diferença interna e que, assim, fala da sociedade.

\section{Referências bibliográficas}

CARNEIRO DA CUNHA, Manuela. Os mortos e os outros: uma análise do sistema funerário e da noção de pessoa entre os Krahó. São Paulo: Hucitec, 1978.

COELHO DE SOUZA, Manuela. O traço e o círculo: o conceito de parentesco entre os Jê e seus antropólogos. 2002. 668 f. Tese (Doutorado em Antropologia Social) - Museu Nacional de Antropologia, Universidade Federal do Rio de Janeiro, Rio de Janeiro, 2002.

COHN, Clarice. A ornamentação corporal das crianças mebengokré-xikrin. In: Encontro Anual da ANPOCS, 33, 2009, pp. 25. Caxambu. Anais. Encontro Anual da ANPOCS, Caxambu.

DA MATTA, Roberto. Um mundo dividido: a estrutura social dos índios Apinayé. Petrópolis: Vozes, 1976.

DELEUZE, Gilles. A imagem-movimento: Cinema 1. São Paulo: Brasiliense. 1985.

A imagem-tempo: Cinema 2. São Paulo: Brasiliense, 1990.

DEMARCHI, André. A arte do contato: arte, xamanismo, guerra e contato entre os Mebengokre-Kayapó. 2009. 70 f. Projeto de qualificação - Universidade Federal do Rio de Janeiro, Rio de Janeiro, 2009.

É a pintura corporal, cultura material? Notas sobre a pintura corporal Mebengôkre-Kayapó. In: Reunião de Antropologia Brasileira, Belém, 27, 2010, pp. 21.

FOUCAULT, Michael. A ordem do discurso. São Paulo: Loyola, 1996. 
DIEGO MADI DIAS e ANDRÉ DEMARCHI - A imagem cronicamente imperfeita...

GELL, Alfred. A tecnologia do encanto e o encanto da tecnologia. Revista Concinnitas, Rio de Janeiro, v. 6, n. 8, p. 41-63, 2005.

GORDON, Cesar. Economia Selvagem: mercadoria e ritual entre os índios XikrinMebêngôkre. São Paulo: ISA/UNESP/NUTI, 2006.

O valor da beleza: reflexões sobre uma economia estética de objetos entre os Xikrin (Mebengokre-Kayapo). Brasília: BAN/UnB, 2009. (Série Antropologia, 424).

HARAWAY, Donna. Manifesto ciborgue. In: HARAWAY, Donna; KUNZRU, Hari; TADEU, Tomaz (Org.). Antropologia do ciborgue: as vertigens do pós-humano. Belo Horizonte: Autêntica, 2009. p. 17-41.

INGOLD, Tim. The Perception of the Environment: essays in Livelihood, Dwelling and Skill. London: Routledge, 2000.

LEA, Vanessa. Nomes e nekrets Kayapó: uma concepção de riqueza. 1986. 567f. Tese (Doutorado em Antropologia Social) - Museu Nacional de Antropologia, Universidade Federal do Rio de Janeiro, Rio de Janeiro, 1986.

LÉVI-STRAUSS, Claude. O Cru e o Cozido (Mitológicas I). São Paulo: Cosac Naify, 1964 [2004].

Anthropologie structural. Paris: Plon, 1956 [2009].

MADI DIAS, Diego. Mekaron Ipex: cultura, corpo, comunicação e alteridade. Usos do vídeo entre os Mebêngôkre-Kayapó. 2011. 162 f. Dissertação (Mestrado em Antropologia) - Instituto de Filosofia e Ciências Sociais, Universidade Federal do Rio de Janeiro, Rio de Janeiro, 2011.

MAUSS, Marcel. As técnicas corporais. In: Sociologia e antropologia. São

Paulo: Cosac Naify, 2003. p. 399-422.

MAYBURY-LEWIS, David (Org.). Dialectical Societies: the Gê and Bororo of Central Brazil. Cambridge: Harvard University Press, 1979.

NIMUENDAJU, Curt. The Eastern Timbira. Berkley: University of California Press, 1946.

PEIRCE, Charles Sanders. Semiótica. São Paulo: Ed. Perspectiva, 2000.

SEEGER, Anthony; DA MATTA, Roberto; VIVEIROS de CASTRO, Eduardo. A construção da pessoa nas sociedades indígenas brasileiras. In: Boletim do Museu Nacional, Rio de Janeiro, n. 32, p. 2-19, 1979.

STOLZE LIMA, Tania. O que é um corpo? Religião e Sociedade, São Paulo, v. 22, n. 1, p. 9-19, 2002. 
TAYLOR, Anne-Christine et al. Qu' est-ce qu' un corps? Paris: Flammarion/Musée du Quai Branly, 2006.

TURNER, Terence. Social structure and political organization among the Northern Cayapó. Cambridge: Harvard University, 1966.

Defiant Images: The Kayapo appropriation of video. Anthopology Today, Londres, v. 8, n. 6, p. 5-16, dez. 1992.

Social body and embodied subject: bodiliness, subjectivity and sociality among the Kayapó. Cultural Anthropology, Washington, v. 10, n. 2, p. 143-170, 1995.

Baridjumoko em Altamira. In: Povos Indígenas do Brasil. São Paulo: ISA, 1991. p. 172-179.

VERTOV, Dziga. "NÓS - variação do manifesto", "Revolução do conselho dos três", "Nascimento do cine-olho", "Extrato do ABC dos kinoks". In: XAVIER, Ismail (Org). A experiência do cinema: antologia. Rio de Janeiro: Edições Graal / Embrafilme, 1983.

VIDAL, Lux. Morte e Vida de uma Sociedade Indígena Brasileira. São Paulo: Hucitec, 1977.

VIVEIROS DE CASTRO, Eduardo. A fabricação do corpo na sociedade xinguana. In: OLIVEIRA FILHO, João Pacheco de (Org.). Sociedades indígenas e indigenismo no Brasil. Rio de Janeiro: UFRJ / Marco Zero, 1987. p. 31-41.

Os Pronomes Cosmológicos e o Perspectivismo Ameríndio. Mana, Rio de Janeiro, v. 2, n. 2, p. 115-144, out. 1996.

XAVIER, Ismail (Org.). Experiência do cinema: antologia. Rio de Janeiro: Graal, 1983. 